Polymer Journal, Vol. 38, No. 8, pp. 807-813 (2006)

(C) 2006 The Society of Polymer Science, Japan

\title{
Polymer Grafting onto Carbon Black by Solid State Method
}

\author{
Haiyan $\mathrm{XU},{ }^{1,2}$ Binyao $\mathrm{LI}^{2},{ }^{2}$ and Chifei $\mathrm{WU}^{2 \dagger}$ \\ ${ }^{1}$ Key Laboratory of Ministry of Agriculture for Natural Rubber Processing, Zhanjiang 524001, P. R. China \\ ${ }^{2}$ Polymer Alloy Laboratory, School of Materials Science and Technology, \\ East China University of Science and Technology, Shanghai 200237, P. R. China
}

(Received March 9, 2006; Accepted April 14, 2006; Published July 7, 2006)

\begin{abstract}
To modify carbon black (CB) surface, the in situ grafting of natural rubber (NR) onto the CB surface by solid state method was investigated. The torque value of $\mathrm{CB} / \mathrm{NR}$ blend system in Haake internal mixer and FT IR spectra of grafted carbon black (GCB) illuminated that the grafting reaction took place and the decomposed NR was grafted onto the $\mathrm{CB}$ surface. From the TGA results the grafting percentage of NR onto $\mathrm{CB}$ was determined to be from $7.3 \%$ to $44.0 \%$. The Orthogonal design (ORD), which was used to investigate which process parameter significantly influenced the grafting reaction, showed that the degradation time of NR and mixing temperature played an important role in the grafting process. Based on above results, it was considered that the grafting mechanism is radical reaction of the active radical of $\mathrm{CB}$ formed by shear force and polymer radical formed by NR decomposition. In addition, the mechanical properties of vulcanized NR filled with GCB were enhanced to a large extent compared with CB system. [doi:10.1295/polymj.PJ2005248]

KEY WORDS Carbon Black / Surface Grafting of Polymer / Solid State Method / Orthogonal Design / Mechanical Properties /
\end{abstract}

$\mathrm{CB}$ is a very important reinforcing agent in the rubber industry because it can remarkably improve the mechanical, electrical and other properties of elastomeric polymer. The very high surface area of CB creates a large interfacial area between the fillers and the matrix which gives rise to a high interfacial tension between the blend components, so the dispersion of $\mathrm{CB}$ in the matrix and particle-polymer interactions is crucial to the composite performance. ${ }^{1,2}$ To improve its dispersibility, the surface grafting of polymer onto $\mathrm{CB}$ is one of the effective methods. ${ }^{3,4} \mathrm{CB}$ is known to be a strong radical scavenger due to the presence of polycondensed aromatic rings and quinonic and phenolic oxygen, ${ }^{5}$ so propagating polymeric radicals can be easily trapped by $\mathrm{CB}$ surfaces during polymerization. Polymers can also be grafted onto $\mathrm{CB}$ if they can dissociate and form radicals.

Usually there are two ways to graft polymer onto CB. ${ }^{6,7}$ The first is "grafting onto" which involves either the reaction of reactive macromolecules with surface groups or the surface trapping propagating polymer chains. The second is "grafting from" which involves surface initiation then subsequent polymer grew from the surface. Tsubokawa and co-workers ${ }^{8-10}$ have reported some other methods to graft polymer by CB surface trapping polymer radicals which was formed by thermal decomposition of some polymers such as azo, peroxide polymer and so on.

Although grafting of $\mathrm{CB}$ has received much scientific and technological attention, grafted $\mathrm{CB}$ was not suitable to be applied industrially until now because CB was generally grafted in solvent by which the output and efficiency of grafted CB production was greatly low. It is strongly required to propose a new way to modify $\mathrm{CB}$, which can be effectively applied industrially, that is to say, to make GCB by solid state method.

Orthogonal design (ORD) is known to be an effective approach for the design of experiments. The variables of ORD are named "factors", and the settings of each factor are named "levels". ${ }^{11,12}$ The ORD is presented as an orthogonal array with the number of columns corresponding to the number of different factors whose effects will be investigated. The number of rows is equal to the number of runs to be performed, and each row represents combination of factors and levels for one particular run. Suppose there is a four-factor experiment, with each factor having three levels. Traditionally, the experiment will need performing as many as $3^{4}$ (81)-run combinations. ORD combines different factors at specific levels and dramatically reduces the number of runs and at the same time enough information is ensured to perform a full analysis. In the above example, the ORD can generate as minimal as 9-run combinations, considerably decreasing experimental time and costs.

In this paper, a novel way to graft polymer onto $\mathrm{CB}$ is presented which was carried out by solid state method. NR was decomposed to form polymer radical which was grafted by CB surface. The influence

${ }^{\dagger}$ To whom correspondence should be addressed (Tel: +86-21-64252569, Fax: +86-21-64252569, E-mail: wucf@ecust.edu.cn). 
of temperature, speed and mixing time on the property of GCB was discussed by ORD approach. The mechanism of grafting was also proposed.

\section{EXPERIMENTAL}

\section{Materials and Sample Preparation}

$\mathrm{CB}$, intermediate super abrasion furnace black (ISAF, grade N220) was supplied by Mitsubishi Chemical Industry LTD (Japan). The diameters of the primary particles of N220 are $20-25 \mathrm{~nm}$. Its dibutylphthalate (DBP) absorption value, which was used as the degree of filler structure, is $114 \pm 5 \mathrm{~mL} /$ $100 \mathrm{~g}$. The surface areas (nitrogen adsorption value) are $115 \pm 5 \mathrm{~m}^{2} / \mathrm{g}$ for N220. NR (RSS 3) was purchased from Teck Bee Hang (Thailand), having Moony viscosity $\left(\mathrm{M}_{\mathrm{L}} 1+4\right.$ at $\left.100^{\circ} \mathrm{C}\right)$ of 80 and $M_{\mathrm{w}}$ of $1,200,000$. All other raw materials used were commercial grade.

NR-grafted CB (GCB) samples were made in Haake Rheomix600p internal mixer using a chamber of $70 \mathrm{cc}$. In this study, the weight proportion of NR and $\mathrm{CB}$ is chosen to be 1:1. After NR was decomposed for some time at applied high temperature and certain screw speed, CB was added to blend with decomposed NR, and then the NR-grafted CB was obtained.

\section{$T G A$}

In order to determine the percentage of grafting, which can be calculated from Thermogravimetric analysis (TGA) results, polymer-grafted CB must be isolated from ungrafted polymer as following procedure. GCB was extracted in a Soxhlet apparatus with toluene for more than $100 \mathrm{~h}$ until no more NR could be detected in the extracted solvent. The percentage of grafting was determined according to equation (1).

$$
\text { Grafting }(\%)=(\mathrm{A} / \mathrm{B}) \times 100 \%
$$

Here A (g) was the amount of NR grafted onto the $\mathrm{CB}$ which was determined by weight loss when $\mathrm{B}(\mathrm{g})$ GCB was heated at $500^{\circ} \mathrm{C}$ in TGA tests.

TGA tests were performed with a Netzsch TG 209 in a nitrogen atmosphere, being in the temperature range of between room temperature and $800^{\circ} \mathrm{C}$ and a rate of heating of $10 \mathrm{~K} \mathrm{~min}^{-1}$. The mass of samples were between 6.0 and $10.0 \mathrm{mg}$.

\section{ORD}

In the present investigation, a four process parameters, i.e., mixing temperature, mixing speed, time of NR degradation before $\mathrm{CB}$ was added and the amount of $\mathrm{CB}$ and NR in Haake internal mixer chamber are considered. Each factor contained three levels, as shown in Table I.
Table I. Distribution of three levels of four factors used for the ORD method

\begin{tabular}{ccccc}
\hline \multirow{2}{*}{ Level } & \multicolumn{4}{c}{ Factor } \\
\cline { 2 - 5 } & $\mathrm{A}\left({ }^{\circ} \mathrm{C}\right)$ & $\mathrm{B}(\mathrm{rpm})$ & $\mathrm{C}(\min )$ & $\mathrm{D}(\mathrm{g})$ \\
\hline 1 & 140 & 60 & 5 & 40 \\
2 & 160 & 80 & 10 & 50 \\
3 & 180 & 100 & 15 & 60 \\
\hline
\end{tabular}

${ }^{*}$ Factor $\mathrm{A}$ is mixing temperature, ${ }^{\circ} \mathrm{C}$; Factor $\mathrm{B}$ is mixing speed, i.e., rotating speed of Haake internal mixer screw, rpm; Factor $\mathrm{C}$ is the time of NR degradation before $\mathrm{CB}$ added, minutes; Factor D is the amount of materials in Haake internal mixer chamber, and the weight proportion of $\mathrm{CB}$ and NR is $1: 1$.

According to the ORD method, a minimal 9run orthogonal array $\left(\mathrm{L}_{9}\left(3^{4}\right)\right.$ could be used to find out the effect of different reaction condition on the grafting of $\mathrm{CB}$ with decomposed NR. Each experiment ended 20 min later after $\mathrm{CB}$ was added to the chamber of Haake internal mixer. This design involves nine separate experiments, which are listed in Table II.

In Table II, $K_{i}$ represents the grafting percentage sum of level $\mathrm{i}$ and is calculated according to the following equation:

$$
\mathrm{K}_{\mathrm{i}}=\sum x_{\mathrm{i}(\mathrm{i}=1,2,3)}
$$

Where $x_{\mathrm{i}}$ is the grafting percentage of level $\mathrm{i}$ for certain factor. For example, for factor $\mathrm{A}, \mathrm{K}_{1}$ is calculated as: $\mathrm{K}_{1}=23.1+16.7+7.8=47.6$. Other $\mathrm{K}_{\mathrm{i}}$ can be obtained by the same calculation.

Parameter $k_{i}$ in Table III is the average grafting percentage of level i for certain factor, which is computed using eq 3 :

$$
\mathrm{k}_{\mathrm{i}}=\mathrm{K}_{\mathrm{i}(\mathrm{i}=1,2,3)} / 3
$$

For instance, $\mathrm{k}_{1}$ is calculated as: $\mathrm{k}_{1}=\mathrm{K}_{1} / 3=15.9$ for factor A.

For different factor, range is determined by eq 4 :

$$
\text { Range }=\mathrm{k}_{\mathrm{i}}{ }^{\text {biggest }}-\mathrm{k}_{\mathrm{i}}{ }^{\text {smallest }}{ }_{(\mathrm{i}=1,2,3)}
$$

$\mathrm{T}$ is the total grafting percentage of all designed nine experiments. $\mathrm{T}$ should equal to the sum of $\mathrm{K}_{\mathrm{i}}$ of each factor. $t$ is the average grafting percentage of these nine experiments and it should equal to the sum of $k_{i}$ of each factor.

\section{ATR-FT IR}

Samples extracted by toluene were dried in vacuum. Attenuated total reflection fourier transform infrared spectroscopy (ATR-FT IR) spectra were recorded at room temperature on a Perkin Elmer system 2000 FT-IR apparatus made up of 64 scans with a nominal resolution of $2 \mathrm{~cm}^{-1}$. 
Grafted Carbon Black with Decomposed NR by Solid State Method

Table II. Protocol of the nine experiments from the ORD method

\begin{tabular}{|c|c|c|c|c|c|c|c|c|c|}
\hline \multirow{2}{*}{ Run } & \multicolumn{2}{|c|}{$\mathrm{A}\left({ }^{\circ} \mathrm{C}\right)$} & \multicolumn{2}{|c|}{$\mathrm{B}(\mathrm{rpm})$} & \multicolumn{2}{|c|}{$\mathrm{C}(\mathrm{min})$} & \multicolumn{2}{|c|}{$\mathrm{D}(\mathrm{g})$} & \multirow{2}{*}{$\begin{array}{c}\text { Grafting } \\
\text { percentage } \\
(\%)\end{array}$} \\
\hline & level & value & level & value & level & value & level & value & \\
\hline 1 & 1 & 140 & 1 & 60 & 1 & 5 & 1 & 40 & 23.1 \\
\hline 2 & 1 & 140 & 2 & 80 & 2 & 10 & 2 & 50 & 16.7 \\
\hline 3 & 1 & 140 & 3 & 100 & 3 & 15 & 3 & 60 & 7.8 \\
\hline 4 & 2 & 160 & 1 & 60 & 2 & 10 & 3 & 60 & 16.8 \\
\hline 5 & 2 & 160 & 2 & 80 & 3 & 15 & 1 & 40 & 7.3 \\
\hline 6 & 2 & 160 & 3 & 100 & 1 & 5 & 2 & 50 & 21.2 \\
\hline 7 & 3 & 180 & 1 & 60 & 3 & 15 & 2 & 50 & 10.8 \\
\hline 8 & 3 & 180 & 2 & 80 & 1 & 5 & 3 & 60 & 37.9 \\
\hline 9 & 3 & 180 & 3 & 100 & 2 & 10 & 1 & 40 & 44.0 \\
\hline $\mathrm{K}_{1}$ & & 47.6 & & 50.7 & & 82.2 & & 74.4 & \\
\hline $\mathrm{K}_{2}$ & & 45.3 & & 61.9 & & 77.5 & & 48.7 & $\mathrm{~T}=185.6$ \\
\hline $\mathrm{K}_{3}$ & & 92.7 & & 73.0 & & 25.9 & & 62.5 & \\
\hline $\mathrm{k}_{1}$ & & 15.9 & & 16.9 & & 27.4 & & 24.8 & \\
\hline $\mathrm{k}_{2}$ & & 15.1 & & 20.6 & & 25.8 & & 16.2 & $\mathrm{t}=61.9$ \\
\hline $\mathrm{k}_{3}$ & & 30.9 & & 24.3 & & 8.6 & & 20.8 & \\
\hline Range & & 15.8 & & 7.4 & & 18.8 & & 8.6 & \\
\hline
\end{tabular}

Table III. Recipe and cure condition for preparation of the rubber samples

\begin{tabular}{ll}
\hline Ingredient & Composition $(\mathrm{phr})^{\mathrm{a}}$ \\
\hline NR & 100 \\
Zinc oxide & 5.0 \\
Stearic acid & 3.0 \\
Antioxidant(AO-20) & 2 \\
Carbon black & Variable \\
Sulfur & 2.5 \\
Accelerator $\mathrm{CZ}^{\mathrm{b}}$ & 0.4 \\
Accelerator $\mathrm{DM}^{\mathrm{c}}$ & 1 \\
\hline
\end{tabular}

${ }^{\mathrm{a}} \mathrm{phr}$, parts per hundred parts rubber. ${ }^{\mathrm{b}} \mathrm{N}$-cyclohexyl-2-benzothiazole sulphenamide. ${ }^{\mathrm{c}}$ dibenzothiazole disulfide.

\section{TEM}

For TEM observation, CB and GCB samples were dispersed into alcohol with an ultrasonic bath. And then the dispersion was dropped onto copper mesh with carbon supporting film. The TEM observation was performed with a JEOL JEM-2010 electron microscope at an accelerating voltage of $200 \mathrm{kV}$.

\section{Mechanical Properties}

NR-grafted CB (GCB) was filled into NR according to the formulation as Table III. Compounding was performed in an open two-roll mixing mill $(\varphi 160)$ at a friction ratio of 1.2. Mixing time of GCB and NR was 10 min while mixing time of $\mathrm{CB}$ and NR was $30 \mathrm{~min}$. Then the composites were cured at $140^{\circ} \mathrm{C}$ for optimum cure time determined by a MDR2000.

Dumb-bell specimens were cut and tested according to ASTM D412. Tear strength was measured on unnotched 90-angle testing specimens according to
ASTM D624. The tests were performed with an Instron 4465 universal testing machine at a crosshead speed of $500 \mathrm{~mm} / \mathrm{min}$. Shore A hardness was measured with a Shore Instrument according to ASTM D2240-75.

\section{RESULTS AND DISCUSSION}

\section{Grafting of NR onto the Carbon Black Surface}

Tsubokawa et al. have reported that polymer radicals formed by the thermal decomposition of azo polymers $^{8}$ and peroxide polymers ${ }^{9}$ are effectively trapped by polycondensed aromatic rings of the $\mathrm{CB}$ surface to give the corresponding polymer-grafted $\mathrm{CB}$. Therefore, the grafting reaction of the $\mathrm{CB}$ surface with NR radicals formed by the thermal dissociation was examined in this paper.

It is known that rheological measurements are often used to demonstrate the occurrence of compatibilisation reactions. ${ }^{13}$ Accordingly, simultaneous torque measurements were performed in order to obtain an idea about the occurring reactions and the viscosity changes. The torque value is known to be related to the viscosity of the blend system within the mixing chamber. A chemical reaction taking place between the reactive blend components will lead to an increase of the blend viscosity (torque) compared to a mixture without any reaction. Therefore, Haake Rheomix600p internal mixer was used to prepare the grafted $\mathrm{CB}$ and investigate the grafting reaction.

Figure 1 presents the torque response as a function of the mixing time for pure $\mathrm{CB}$ and $\mathrm{NR}$ and various compositions of $\mathrm{CB} / \mathrm{NR}$ blend system. NR displays 


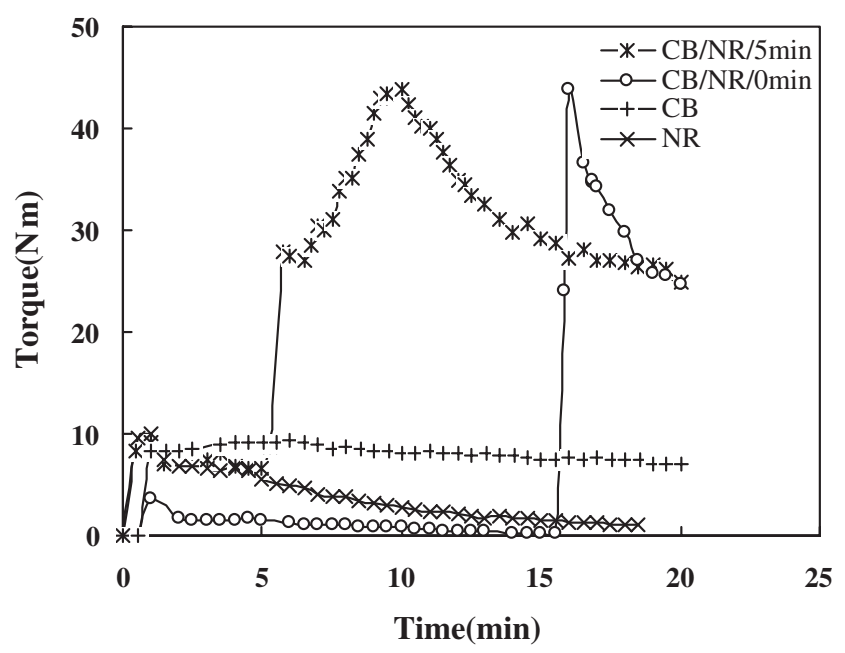

Figure 1. Torque response as a function of the mixing time for pure $\mathrm{CB}$, pure NR and different NR/CB blend system, respectively.

a low torque value, representative of a low viscosity. A continuous decrease of the torque response can be observed due to thermal and/or oxidative chain degradation of $\mathrm{NR}$ at the applied mixing temperature of $180^{\circ} \mathrm{C}$. Pure $\mathrm{CB}$ displays a much higher resulting torque value compared to that of $\mathrm{NR}$ and the torque value almost keeps constant during the applied mixing time. The CB/NR blend systems reveal different behaviors, depending on their process. There are two $\mathrm{CB} /$ NR blend systems in Figure 1. One is CB/NR/0 min which represents that $\mathrm{CB}$ and $\mathrm{NR}$ were put together into the Haake mixer chamber at beginning. The other is $\mathrm{CB} / \mathrm{NR} / 5$ min which means that $\mathrm{NR}$ was put into the chamber at first and mixed for $5 \mathrm{~min}$, and then $\mathrm{CB}$ was added to blend with NR for $15 \mathrm{~min}$.

The torque curve of $\mathrm{CB} / \mathrm{NR}$ blend system when $\mathrm{CB}$ and NR were added together exhibit lower value, followed by a continuous decrease during $15 \mathrm{~min}$, which can thus attributed to the chain decomposition of NR. An interesting feature to be noted is that the resulting torque value of $\mathrm{CB} / \mathrm{NR} / 0 \mathrm{~min}$ after $15 \mathrm{~min}$ of mixing, increase abruptly to as high as more than $40 \mathrm{Nm}$. It is obvious that the observed torque increase cannot be accounted for other materials because no other reagents were added into the blend systems during this processing. The additional viscosity increase needs to be attributed to the occurrence of grafting reaction of $\mathrm{CB}$ and polymer radicals formed by the decomposition of NR. In the system of CB/NR/5 min, after CB was added the torque curve increases promptly and reaches a peak several minutes later. The grafting reaction can also be held responsible similar to $\mathrm{CB}$ / NR/0 min system.

The grafting reaction of $\mathrm{CB}$ and degraded NR was investigated by ATR-FT IR spectra. As shown
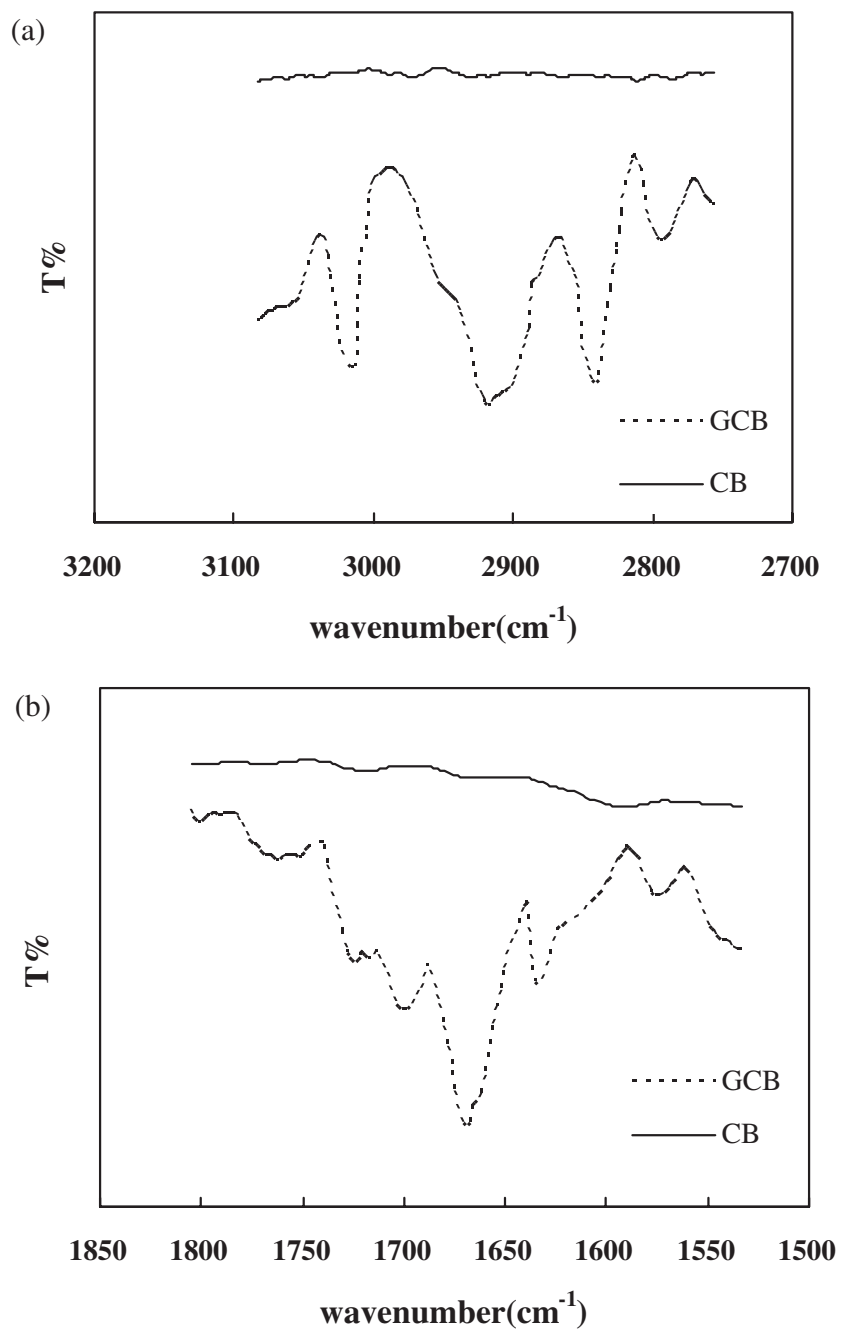

Figure 2. FT IR spectra of original $\mathrm{CB}$ and $\mathrm{NR}$ grafted $\mathrm{CB}$ from 2700 to $3200 \mathrm{~cm}^{-1}$ (a), and from 1500 to $1850 \mathrm{~cm}^{-1}$ (b).

in Figure 2a, it is apparent that the IR spectra of NR-grafted CB reveal new absorptions around 3000 $\mathrm{cm}^{-1}$ compared with that of original $\mathrm{CB}$, which is due to the $-\mathrm{CH}$ and the $=\mathrm{CH}$ group of grafted NR. Similar to Figure $2 a$, it was observed in Figure $2 b$ that there were new peaks around $1650 \mathrm{~cm}^{-1}$ which could be assigned to $-\mathrm{C}=\mathrm{O}$ group. Obviously the $-\mathrm{C}=\mathrm{O}$ group was introduced into the $\mathrm{CB}$ surface by degraded NR because there was no $-\mathrm{C}=\mathrm{O}$ peak in $\mathrm{CB}$ and raw NR, so it can be concluded that the NR was decomposed with thermal and oxidative chain degradation at the high applied mixing temperature as $180^{\circ} \mathrm{C} .{ }^{14,15}$

TEM images of original CB and GCB are shown in Figure 3. It is known that $\mathrm{CBs}$ are made by an aerosol synthesis route, whereby they form aggregate structures (typically $300 \mathrm{~nm}$ to $3 \mu \mathrm{m}$ in dimension) composed of primary particles, which are attached to their immediate neighbors through necklike regions formed by solid-state bonding. Furthermore, the aggregates can form loosely connected structures called agglomerates, which do not have a solid-state bond between 

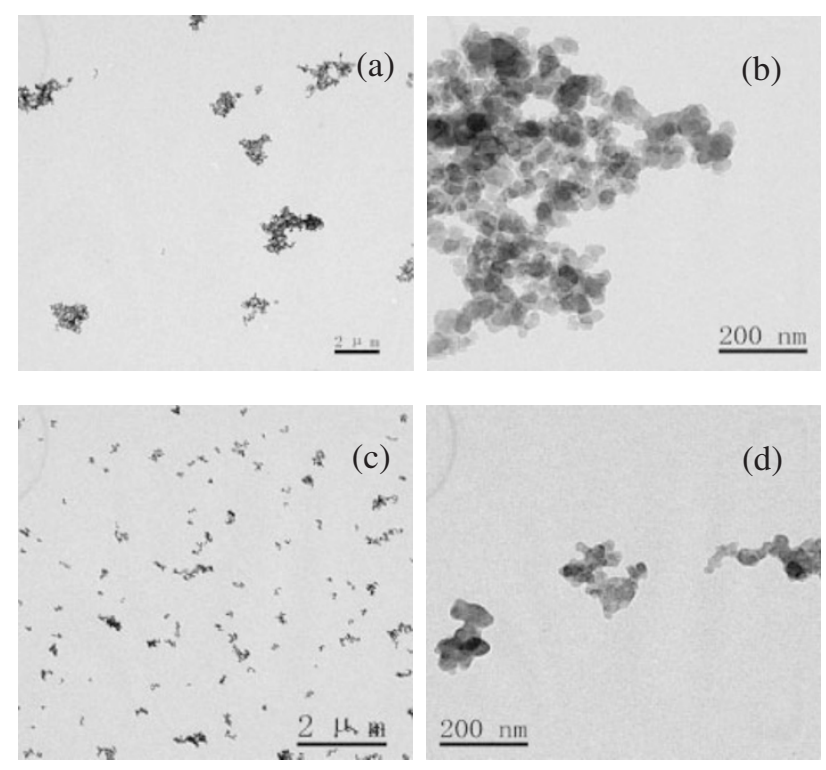

Figure 3. TEM images of original CB $(a, b)$ and NR grafted CB particles (c, d).

them. ${ }^{16}$ From Figure $3 a$ and $3 b$, it can be seen obviously that the original $\mathrm{CB}$ particles fused together and there are many big agglomerates. While in the Figure $3 \mathrm{c}$ and $3 \mathrm{~d}$, the sizes of GCB particles decreased to about $200 \mathrm{~nm}$. The reason why the GCB particles become much smaller is that in the manufacture of GCB materials, agglomerates are broken down to smaller structures, typically to the size of aggregates and the grafting layer prevents the GCB particles conglomerating again during dispersing into solvent.

\section{Grafting Mechanism}

It is well known that there are many radicals on the CB surface, but a strong thought maintains that the radicals are inert because they are stabilized by polycondensed aromatic rings and quinonic oxygen groups on the $\mathrm{CB}$ surface. ${ }^{17,18}$ Hasegawa and co-workers have reported that mechanoradicals were produced by grinding organic powder such as quartz, montamorillonite, limestone and marble. The increase of free radicals formed on the organic particle surface has been confirmed by ESR, and these radicals were found to be active enough to initiate some monomers, for example, methyl methacrylate to proceed with a radical polymerization. ${ }^{19-21}$ Accordingly, it provides powerful evidence to deduce that active free radicals were mechanochemically introduced into $\mathrm{CB}$ surface by strong shear force brought with the screws of Haake internal mixer.

As mentioned above, NR was decomposed with thermal and oxidative chain degradation at the high temperature to give rise to corresponding polymer radicals, which can react with the mechanoradicals on the CB surface. Therefore, NR was bonded to CB.

\section{Orthogonal Design of Grafting Process Variable}

Orthogonal design approach is used to design experiments to identify the optimal preparation conditions and to single out the factors, i.e., mixing temperature, mixing speed, time of NR degradation before $\mathrm{CB}$ was added and the amount of $\mathrm{CB}$ and $\mathrm{NR}$, which have the most significant influence on the grafting reaction. The optimization target was the percentage of grafting, and nine grafting percentage of grafted $\mathrm{CB}$ were obtained through proceed the 9-run experiments. For each factor of grafting reaction, three average resolution data for each of the three levels, respectively, were shown as Table II. The relationship of grafting percentage and each single factor are presented in Figure $4 a-d$ and the level range of each factor is shown in Figure 5.

Figure 4a shows the relationship between percentages of grafting onto $\mathrm{CB}$ and mixing temperature. It was found that the grafting percentage increased with mixing temperature increased, which can be attributed to the high temperature make the thermal degradation of NR more quickly, correspondingly there were much more polymer radicals to be produced and grafted onto the surface of CB.

Figure $4 \mathrm{~b}$ gives the effect of mixing speed on the grafting reaction. It was observed that high mixing speed led to high value of grafting percentage. As is well known, if the mixer screws rotated faster, it can give the materials more powerful shear force. Then the thermal degradation of NR was accelerated and more NR radicals were grafted accordingly.

Before CB was added and mixed with NR, NR was decomposed for some time at high temperature in the field of shear force. The result in Figure $4 \mathrm{c}$ shows that the grafting percentage of grafted CB decreased if the degradation time was prolonged. The reason is considered to be that the decomposed NR radicals tended to be terminated by another NR radical instead of being grafted onto $\mathrm{CB}$ surface if there was no $\mathrm{CB}$ added.

The influence of the amount of $\mathrm{CB}$ and NR on the grafting percentage is given in Figure 4d. A previous thought hold that more NR mixed in Haake mixer chamber would lead to higher shear force that NR were subjected to, which made more NR radicals be produced. But it is surprised that the percentage of grafting does not vary regularly with the amount increase.

It is well known that higher range value of certain factor in ORD experiments means that this factor would have more significant influence on the optimization target, which is the percentage of grafting in this study. It is seen from Figure 5 that the range value of the time of degradation of NR and mixing temperature are obviously bigger than that of the other two factors, indicating that these two factors, i.e., degrada- 

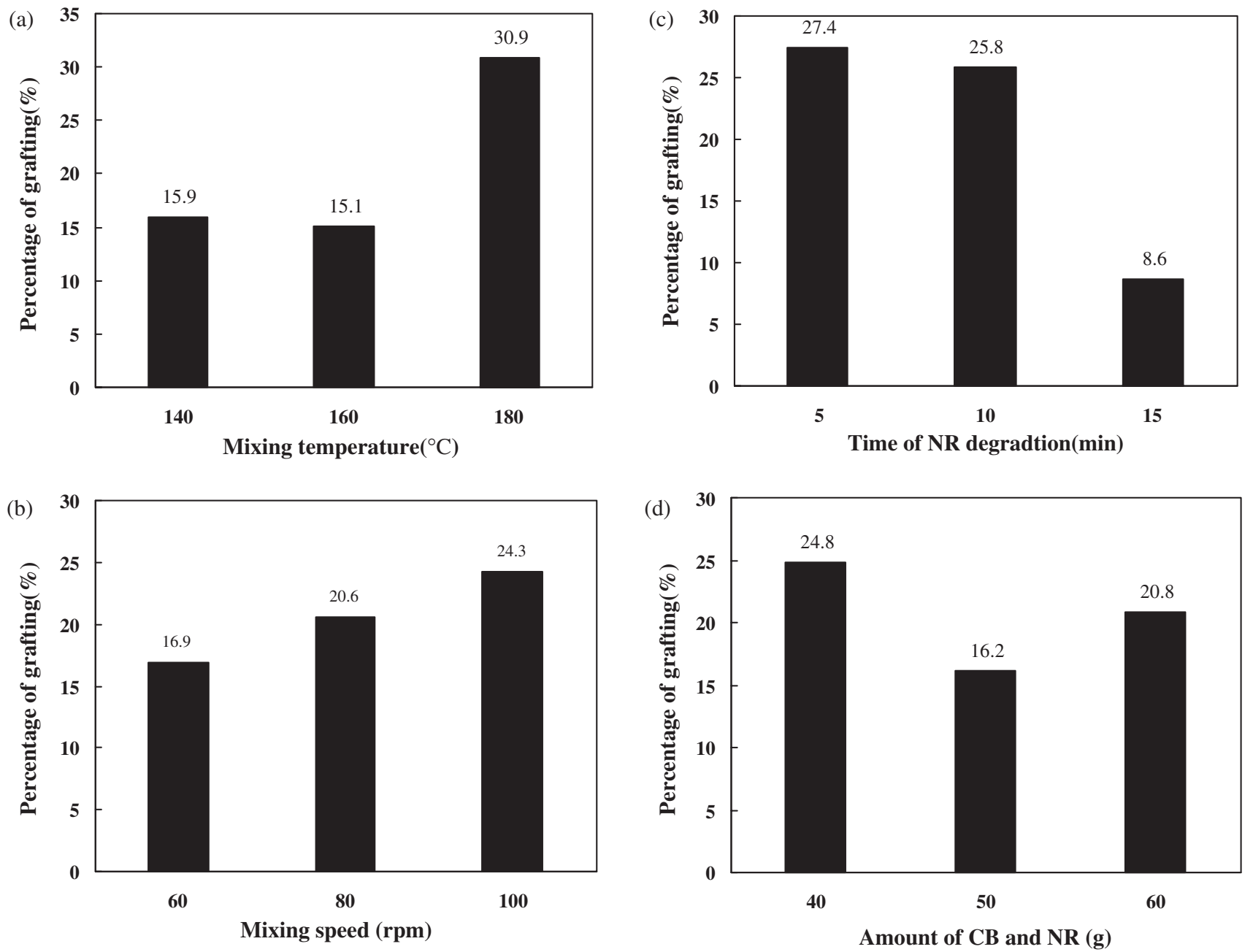

Figure 4. Percentage of grafting as a function of mixing temperature (a), mixing speed (b), time of NR degradation (c), and amount of $\mathrm{CB}$ and NR in Haake internal mixer chamber (d), resulted from ORD experiments.

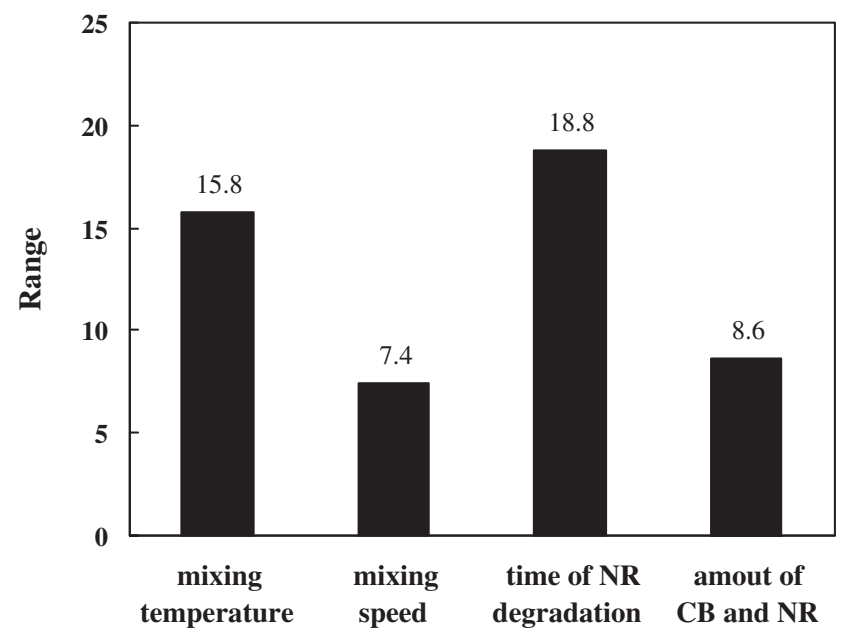

Figure 5. Range values of four factors, i.e., mixing temperature, mixing speed, time of NR degradation and amount of $\mathrm{CB}$ and NR in ORD experiments.

tion time and mixing temperature, are more important in the grafting processing of decomposed NR onto $\mathrm{CB}$ surface.

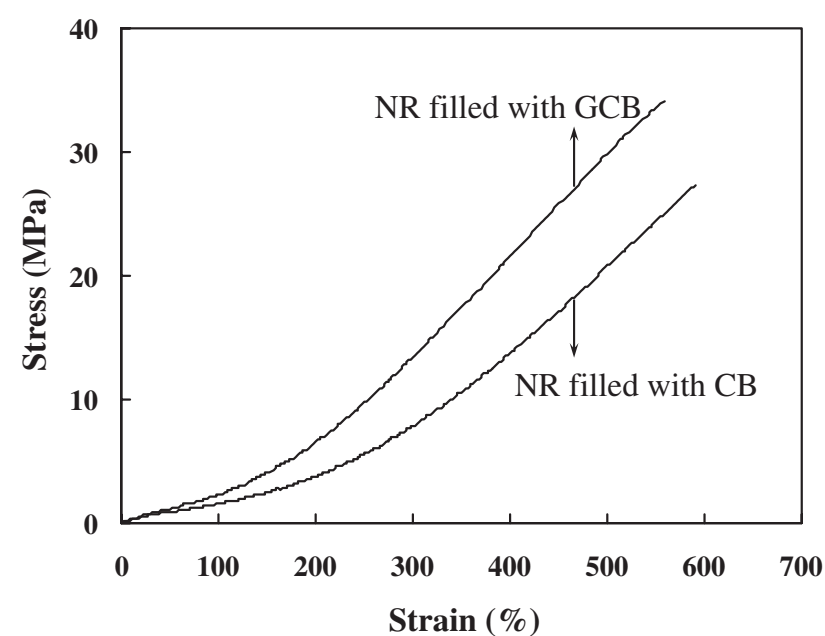

Figure 6. The relationship of strain and stress of vulcanized NR filled with $\mathrm{CB}$ and GCB.

\section{Mechanical Properties}

The effect of GCB on the mechanical properties of vulcanized NR was investigated. The relationship of strain-stress of vulcanized NR filled with $\mathrm{CB}$ and 
Grafted Carbon Black with Decomposed NR by Solid State Method

Table IV. Mechanical properties of vulcanized NR filled with CB and GCB

\begin{tabular}{lccccc}
\hline & $\begin{array}{c}\text { Tensile } \\
\text { strength }(\mathrm{MPa})\end{array}$ & $\begin{array}{c}\text { Elongation } \\
\text { at break }(\%)\end{array}$ & $\begin{array}{c}300 \% \text { modulus } \\
(\mathrm{MPa})\end{array}$ & $\begin{array}{c}\text { Tear } \\
\text { strength }(\mathrm{N} / \mathrm{cm})\end{array}$ & $\begin{array}{c}\text { Hardness } \\
(\text { Shore A) }\end{array}$ \\
\hline GCB filled NR & 34.0 & 591 & 13.5 & 93.6 & 60 \\
CB filled NR & 27.4 & 558 & 7.9 & 75.2 & 57 \\
\hline
\end{tabular}

GCB was presented in Figure 6. The loading of filler is $35 \mathrm{phr}$. All tensile properties of vulcanized NR filled with GCB are improved except elongation at break. The value of tensile properties and other mechanical properties are listed in Table IV. It is also can be seen that tensile strength, 300\% modulus and tear strength of vulcanized NR filled with GCB are enhanced to a large extent. The reason is considered to be that $\mathrm{CB}$ surface was grafted by NR chains, which were as same as polymer matrix, so the filler-polymer interaction was increased. In addition, it is observed that GCB led to higher hardness. The elongation at break of GCB system is observed to decrease a little compared with the CB system, which can be attributed to the decomposition of NR chains grafted onto the CB surface. But this decrease is so mild that it does not influence the characteristic high elasticity of rubber materials. On the basis of above discuss, it is concluded that the grafted $\mathrm{CB}$ can reinforce rubber matrix effectively.

\section{CONCLUSIONS}

Polymer radicals, which were formed by the thermal and oxidative chain degradation of NR, were successfully grafted onto the CB surface by radical reaction with the active radicals of $\mathrm{CB}$ formed by shear force. The grafting was proceeded by solid state method, which is beneficial to make the grafted CB be applied industrially. The ORD results found that the degradation time of NR and mixing temperature played an important role in the grafting process. The mechanical properties of vulcanized NR filled with GCB were largely enhanced for the grafting layer increased the interaction of $\mathrm{CB}$ and NR matrix.

\section{REFERENCES}

1. C. L Wu, M. Q. Zhang, M. Z. Rong, and K. Friedrich,
Compos. Sci. Technol., 62, 1327 (2002).

2. J. E. Mark, J. Phys. Chem. B, 107, 903 (2003).

3. R. Laible and K. Hamann, Adv. Colloid Interface Sci., 13, 65 (1980).

4. N. Tsubokawa, Prog. Polym. Sci., 17, 471 (1992).

5. M. Ley and M. Azwarz, J. Chem. Phys., 22, 1621 (1954).

6. T. Q. Liu, S. J. Jia, T. Kowalewski, and K. Matyjaszewski, Langmuir, 19, 6342 (2003).

7. S. Hayashi, A. Naitoh, S. Machida, M. Okazaki, K. Maruyama, and N. Tsubokawa, Appl. Organomet. Chem., 12, 743 (1998).

8. K. Fujiki, N. Tsubokawa, and Y. Sone, Polym. J., 22, 661 (1990).

9. N. Tsubokawa, K. Fujiki, and Y. Sone, Polym. J., 20, 213 (1988).

10. S. Yoshikawa, S. Mashida, and N. Tsubokawa, J. Polym. Sci., Part A: Polym. Chem., 36, 3165 (1998).

11. A. S. Hedayat, N. J. A. Sloane, and J. Stufken, "Orthogonal Array: Theory and Applications", Springer-Verlag, New York, 1999.

12. F. Xu, M. Jabasini, and Y. Baba, Electrophoresis, 26, 3013 (2005).

13. W. Loyens and G. Groeninckx, Macromol. Chem. Phys., 203, 1702 (2002).

14. M. Edge, N. S. Allen, R. G. Sarchez, C. M. Liauw, S. J. Read, and R. B. Whitehouse, Polym. Degrad. Stab., 64, 197 (1999).

15. N. S. Allen, in "Degradation and stabilization of polyolefins", Applied Science Publishers, London, 1983.

16. R. Bandyopadhyaya, W. Z. Rong, and S. K. Friedlander, Chem. Mater., 16, 3147 (2004).

17. J. B. Donnet, G. Henrich, and L. Geidreich, Compt. Rend., 249, 97 (1959).

18. K. Ohkita, H. Kasahara, N. Ishizuke, and Y. Itagaki, Nippon Gomu Kyokaishi, 30, 36 (1963).

19. M. Hasegawa, S. Kobayashi, and M. Kimita, J. Appl. Polym. Sci., 84, 2011 (2002).

20. S. Kawaguchi, I. Takahashi, H. Tajima, Y. Hirose, and K. Ito, Polym. J., 28, 735 (1996).

21. M. Kimita, I. Takahashi, and M. Hasegawa, J. Soc. Powder Technol., Japan, 41, 259 (2004). 